neofilolog

Czasopismo Polskiego Towarzystwa Neofilologicznego

ISSN 1429-2173, elSSN 2545-3971, 2020, NR 55/2, 225-237

http://dx.doi.org/10.14746/n.2020.55.2.5

http://poltowneo.org/

Anna Waszau

Uniwersytet im. Adama Mickiewicza w Poznaniu https://orcid.org/0000-0002-1847-1295

annsza5@amu.edu.pl

\title{
Czy kultura własna jest potrzebna do rozwijania kompetencji (inter)kulturowej? 0 uwzględnianiu kultury ojczystej w procesie nauczania/uczenia się języka obcego
}

Is one's own culture necessary to develop (inter)cultural competence? On taking the source culture into account in the process of teaching/ learning a foreign language

The purpose of the present article to reflect on the possibilities of developing (inter)cultural competence in the context of glottodidactics by resorting to elements of the source culture, which helps to build (meta)cultural awareness. By analyzing from a diachronic perspective, together with some traditional approaches and modern concepts, it is shown that the evolution of glottodidactic models indicates the need to develop a reflective attitude which is built upon the (meta)cultural awareness. This progress, in turn, requires reflection on one's cultural identity and on the system of one's own culture which influences the socialization and enculturation processes. Therefore, awareness thus conceptualized can help in determining and understanding the organizational and generative principles of cultures, as well as their functioning and mechanisms.

Keywords: meta-cultural awareness, intercultural competence, teaching/learning, source culture

Słowa kluczowe: świadomość metakulturowa, kompetencja interkulturowa, nauczanie/uczenie się, kultura własna 


\section{Wstęp}

W różnych koncepcjach metodycznych glottodydaktyki kładzie się nacisk na kształtowanie nie tylko kompetencji stricte językowych, ale również (inter)kulturowych, niezbędnych do osiągnięcia sukcesu komunikacyjnego. Związane jest to ze ścisłym, niepodważalnym związkiem języka i kultury. Przyjmując za Sapirem (1978), że język jest niejako przewodnikiem po rzeczywistości społecznej, nie dziwi potrzeba rozwijania wiedzy i umiejętności mających wpływ na postawę przyjmowaną wobec Drugiego, umożliwiającą zrozumienie jego zachowania i przekonań. W tym kontekście „jakiekolwiek rozgraniczanie struktur językowych od podłoża kulturowego prowadzić będzie nie tylko do wypaczenia procesu nauki języka, lecz także stanowić poważną przeszkodę na drodze samej nauki języka przez ucznia" (Polok, 2006: 6). Wydaje się, że proces rozwijania kompetencji (inter)kulturowej, związany z analizą kompleksowego systemu (innej) kultury, winien być również oparty na zrozumieniu mechanizmów regulujących kulturę własną - wszakże trudno zrozumieć podejście i motywacje Drugiego, jeśli nie rozumie się ich u siebie.

Celem artykułu jest refleksja dotycząca ewolucji metod i podejść glottodydaktycznych co do miejsca i roli kultury własnej w procesie nauczania/uczenia się języka obcego, odzwierciedlającej się w tożsamości kulturowej uczących się - swego rodzaju „zasobach wstępnych", z którymi uczący się wkraczają w ów proces. Branie pod uwagę tej tożsamości wydaje się mieć z kolei bezpośredni wpływ na budowanie świadomości (meta)kulturowej, pomagającej w kształtowaniu postawy refleksyjnej. W związku z tym, w pierwszej części artykułu omówione zostaną dwa podstawowe zagadnienia, czyli kompetencja (inter)kulturowa (dalej: KI) oraz tożsamość (kulturowa). W kontekście pierwszego terminu przedstawione zostaną wybrane propozycje definicyjne wraz z analizą komponentów KI oraz roli kultury własnej w procesie jej rozwijania. Następnie omówiona zostanie pokrótce tożsamość jako pojęcie odzwierciedlające normy, schematy i wartości właściwe własnej kulturze. Dalej przeanalizowane zostaną, w ujęciu diachronicznym, różne tradycyjne metody i podejścia glottodydaktyczne pod kątem uwzględniania kulturowej tożsamości w budowaniu KI. Po tak przeprowadzonej ewaluacji przedstawione zostaną aktualne tendencje w zakresie konceptualizacji oraz rozwijania KI, ze szczególnym zwróceniem uwagi na coraz wyraźniejsze akcentowanie roli kultury własnej uczących się, wykorzystywanej do budowania świadomości ma poziomie meta. Pozwoli to w zakończeniu na przedstawienie podsumowującej refleksji dotyczącej potencjalnych efektów wynikających z kształtowania u uczących się tejże świadomości, rozwijanej dzięki obserwacji i analizie kultury własnej. 


\section{Kompetencja (inter)kulturowa w ujęciu terminologicznym}

Poruszając kwestię terminu KI należy zaznaczyć, że jest on dzisiaj niezwykle eksploatowany, nie tylko w glottodydaktyce - staje się nawet w pewien sposób „modny” (Bolten, 2006) - co skutkuje m.in. pojawianiem się wielu wyjaśnień tegoż pojęcia (Wilczyńska, 2005). Można jednak wyróżnić w zakresie definiowania pewne tendencje, odnoszące się najczęściej do elementów o charakterze kognitywnym, metakomunikacyjnym oraz afektywnym (Białek, 2017: 16). W tym kontekście podkreśla się również systemowy charakter odnośnej kompetencji, właściwy przecież samej kulturze (por. Keesing, 1974; Golka, 1992). W ramach KI wyróżnia się zazwyczaj takie składowe, jak: wiedza deklaratywna (fr. savoir), wiedza proceduralna (fr. savoir-faire), oraz - co zdaje się być kluczowym ogniwem w wielu modelach (por. Porcher, 1988; Grucza, 1989; Mihułka, 2014) - postawy, uwarunkowania osobowościowe (fr. savoir-être), nawiązujące do tożsamości, ukształtowanej w konkretnej zbiorowości, określonej kulturze. Takie rozumienie KI wynika również ze sposobu, w jaki Europejski system opisu kształcenia językowego (dalej: ESOKJ) definiuje termin samej kompetencji. Jest to „całość wiedzy deklaratywnej, sprawności i umiejętności oraz cechy charakteru danej osoby, które to czynniki determinują jej sposób działania" (ESOKJ, 2003: 20). Analiza różnych koncepcji KI pozwala domniemywać, że oparte są one przede wszystkim na obserwacjach socjologicznych oraz kulturoznawczych, przy uwzględnieniu np. teorii psychologii interkulturowej ${ }^{1}$, ale także oficjalnych regulacji i norm prawnych, takich jak konwencja o ochronie praw człowieka, mniejszości narodowych itp. Co się tyczy celów $\mathrm{KI}$, najogólniej można byłoby je sprowadzić do umiejętności komunikowania interkulturowego, w którym podstawowym warunkiem sukcesu interakcji jest poszanowanie godności Drugiego i sposobu, w jaki ta godność realizuje się w jego własnej kulturze (Wilczyńska, 2005).

Podstawowym oficjalnym dokumentem, do którego w kontekście zinstytucjonalizowanego procesu nauczania/uczenia się języka obcego należałoby się tutaj odwołać, jest wspomniany wyżej ESOKJ. Trzeba zaznaczyć, że w samym dokumencie nie pada explicite termin kompetencja (inter)kulturowa. W ESOKJ (2003: 94-99) mowa jest o „wiedzy socjokulturowej (...) wrażliwości interkulturowej (...) umiejętnościach interkulturowych (...) uwarunkowaniach osobowościowych (...) umiejętnościach heurystycznych (...) kompetencji socjokulturowej". Jak z tego wynika, wszystkie wymienione komponenty składają się na to, co aktualnie rozumie się w glottodydaktyce jako właśnie KI,

\footnotetext{
${ }^{1}$ W odniesieniu do badań np. autorstwa Matsumoto i Juanga (2007), Halla (1976) czy Boskiego (2009).
} 
czyli triadę wymiarów savoir: wiedzy, umiejętności oraz postaw. Ważnym uzupełnieniem dla ESOKJ w kwestii (inter)kulturowości jest inny dokument - tzw. FREPA, czyli System opisu pluralistycznych podejść do języków i kultur². Na pierwszy plan wysuwa się tam pojęcie kompetencji różnojęzycznej oraz międzykulturowej, w ramach której - mimo pewnej atomizacji - sygnalizowana jest istota kształtowania postaw sprzyjających rozwijaniu swego rodzaju świadomości, którą można byłoby odnieść już do poziomu metakulturowego. Co ważne w kontekście naszych rozważań, rozumienie w ten sposób kompetencji, z włączeniem w to istotnej roli świadomości, ma związek z osobowościowymi (savoir-être) "zasobami wstępnymi” uczącego się, nawiązującymi przede wszystkim do jego własnej kultury i tożsamości w niej ukształtowanej.

Podobny sposób rozumienia i definiowania KI uwidacznia się również w innych koncepcjach glottodydaktycznych. Można w tym kontekście przytoczyć np. model tzw. międzykulturowej kompetencji komunikacyjnej Byrama (1991), do którego wrócimy w dalszej części artykułu, a który zwraca szczególną uwagę na kulturowo-społeczny charakter języka. Byram, postulując zintegrowaną naukę języka i kultury, podkreśla istotę świadomości zarówno w wymiarze językowym (ang. language awareness), jak też kulturowym (ang. cultural awareness), i odwołuje się do zasobów kultury własnej uczących się jako swoistego punktu wyjścia. Natomiast na polskim gruncie badawczym, m.in. Wilczyńska (2005) postuluje bazowanie na takim modelu Kl, który uwzględnia również „świadomość metakulturową" w połączeniu z "mediacją interkulturową" oraz „wrażliwością (inter)kulturową”. Wilczyńska (2005: 22) rozumie tym samym $\mathrm{KI}$ jako wielowymiarowe narzędzie niezbędne w komunikacji interkulturowej (por. też Myczko, 2005), a świadomość jako „obejmującą naturę i mechanizmy funkcjonowania kultury" - co wydaje się najbardziej dostępne do obserwacji w kulturze własnej, w której funkcjonuje się na co dzień. Taki sposób konceptualizacji KI sprzyja jej kompleksowemu, wielokierunkowemu rozwojowi, bierze też pod uwagę tożsamość (kulturową) uczących się ${ }^{3}$.

\section{Tożsamość (kulturowa) w świetle KI}

Jeśli, jak wynika z przedstawionych definicji KI, jej kształtowanie odnosi się w dużej mierze do sfery afektywnej uczących się (savoir-être), to nawiązuje

\footnotetext{
${ }^{2}$ Więcej na temat FREPA: https://carap.ecml.at/CARAPinPoland/tabid/3019/Default.aspx [DW: 28.12.2019].

${ }^{3}$ Wilczyńska (2005) w innym miejscu wyraźnie zaznacza, że na różnych poziomach komunikacji posługujemy się innymi „obliczami” tej samej tożsamości - odgrywa ona również znaczącą rolę na poziomie interkulturowym.
} 
tym samym do ich osobowości, a także tożsamości, zazwyczaj już przecież w znacznym stopniu ukształtowanej poprzez socjalizację i enkulturację. Jest ona więc w pewnym sensie odbiciem, odzwierciedleniem różnych nabytych wartości, schematów czy standardów (por. Thomas, 2010) właściwych kulturze, w obrębie której funkcjonuje się na co dzień ${ }^{4}$. Jak określa Thomas (2001, za: ZatorPeljan, 2014: 33), tożsamość jest tym samym „sumą wiedzy danej osoby o jej przynależności do określonej grupy społecznej" - choć definicja ta akcentuje element samej wiedzy, to w wyraźny sposób zaznacza powiązanie tożsamości z odnośną zbiorowością. Istotne jest, że konstruuje się ona zawsze w odniesieniu do innych, najpierw w obrębie własnej społeczności - jako podmioty funkcjonujące na co dzień w danej kulturze, definiujemy się i kształtujemy na jej tle. Z drugiej strony, również spotkanie z Drugim pomaga nam się „określić”: obrazy „Obcego” to w pewnym sensie zwierciadło rozumienia samego siebie (Bolten, 2006), toteż tożsamość definiuje się zawsze w pewnym stopniu w odniesieniu do Drugiego członka innej zbiorowości, reprezentującego inną kulturę (Charaudeau, 2009) ${ }^{5}$. Biorąc pod uwagę proces nauczania/uczenia się, należy w tym miejscu także zaznaczyć, że celem dydaktycznym nie powinno być w żadnej mierze „wymazanie” tejże tożsamości (pomimo iż dąży się do jak najlepszego zrozumienia innych zbiorowości i ich kultur i stawania się nierzadko ich mediatorem we własnej kulturze). Stanowi ona swego rodzaju wspomniane „zasoby wstępne”, podlegające pewnemu modelowaniu (por. Myczko, 2005; Białek, 2017), np. w procesie edukacji, równomiernie z rozwojem wiedzy deklaratywnej i proceduralnej.

W kontekście tych rozważań warto również uwzględnić dwa bieguny tożsamości kulturowej (Wilczyńska, 2005): indywidualny oraz społeczny. Podczas gdy pierwszy uwydatnia się w obrębie funkcjonowania we własnej kulturze, drugi uwidacznia się dopiero w zetknięciu z Drugim. Nie są to osobne konstrukty, lecz jedna integralna tożsamość, która w zależności od kontekstu, sytuacji uaktywnia dane "oblicze". Tym samym w kontaktach interkulturowych to właśnie przynależność do określonej zbiorowości, utożsamianie się z jej normami, wartościami i standardami wyznacza to, kim jest dany uczestnik komunikacji i według jakich mechanizmów sam działa jako podmiot kulturowy.

\footnotetext{
${ }^{4}$ Należy tu przy okazji zaznaczyć, że nie w każdym przypadku musi być ona tożsama z kulturą, w której się urodziliśmy, lecz na przykład z tą, która nas ukształtowała jako jednostki społeczne.

${ }^{5}$ Jak pisze Charaudeau (2009): „Postrzeganie inności, odmienności drugiego stanowi przede wszystkim dowód własnej tożsamości: on jest inny niż ja, więc ja jestem inny niż on, a zatem istnieję". (tłumaczenie własne autorki, fr.: „La perception de la différence de l'autre constitue d'abord la preuve de sa propre identité : " il est différent de moi, donc je suis différent de lui, donc j'existe " „).
} 
Uświadomienie uczącym się, jak kształtuje się oraz jak funkcjonuje ich własna tożsamość, opierająca się w dużej mierze na kulturze, która dostarczyła im wzorców i wartości kulturowych, może mieć zatem zasadnicze znaczenie w kontekście rozwijania KI, odnosząc się jednocześnie do jej kluczowego elementu afektywnego. Zrozumienie działania oblicza indywidualnego oraz społecznego tejże tożsamości pozwala w szerszy sposób dotrzeć do norm i standardów, jakie motywują zachowanie zarówno własne, jak i Drugiego. Wydaje się jednak, że do tej pory na zajęciach językowych oraz w materiałach dydaktycznych mało uwagi poświęcało się zarysowanej wyżej problematyce, zwłaszcza pod kątem konkretnych zadań, co nierzadko przekłada się na trudności komunikacyjne uczących się w przestrzeni interkulturowej.

\section{Ujęcie diachroniczne - kultura własna i tożsamość w KI}

Kultura własna uczących się oraz ukształtowana w niej tożsamość w różnym stopniu była - i jest - uwzględniana w różnych koncepcjach związanych z procesem nauczania/uczenia się języka obcego. Należałoby na wstępie zauważyć, że klasyczne podejścia glottodydaktyczne skupiały się przede wszystkim (jeśli nie wyłącznie) na elementach kultury docelowej związanej z nauczanym językiem. Dominowało podejście podawcze, oparte na przekazywaniu wiedzy faktograficznej, dotyczącej przede wszystkim „kultury wysokiej” (por. Myczko, 2005), którą można za Kramsch (1991: 218) nazwać „"4F”, czyli „ffood, fairs, folklore, statistical facts”.

Jedna z najstarszych metod nauczania/uczenia się języka obcego, czyli gramatyczno-tłumaczeniowa, opowiada się za takim kognitywnym podejściem do nauczania kultury powiązanej z danym językiem (Mackiewicz, 2005) ${ }^{6}$. Uwaga skupia się na wiedzy deklaratywnej, pomijając kwestię tożsamości i kultury uczących się. W tym kontekście kształtowanie interesującej nas kompetencji ogranicza się do rozwijania znajomości faktów czy zjawisk dotyczących tylko kultury docelowej, poznawanych często za pośrednictwem tekstów literackich, stanowiących podstawowy materiał dydaktyczny.

W innej z klasycznych metod, opartej na tzw. „drylu” językowym, czyli audiolingwalnej, brakuje wyraźnego odwołania do treści kulturowych, są one zasadniczo tylko tłem dla prezentowanych sytuacji i dialogów w ćwiczeniach językowych (Neuner, 2003). Proces nauczania/uczenia się polega na reprodukcji utartych wyrażeń i odtwarzaniu ról społecznych, trudno więc mówić o właściwym kształtowaniu KI, a kultura własna uczących się wydaje się całkiem

\footnotetext{
${ }^{6}$ Przyjmuję klasyfikację przedstawioną w artykule Mackiewicza (2005: 56), rozróżniającą podejście kognitywne, komunikacyjne oraz interkulturowe w kwestii nauczania treści kulturowych.
} 
zbagatelizowana. Zgłębianie mechanizmów kulturowych, ułatwiające refleksję na poziomie meta, nie jest tym samym traktowane jako cel pedagogiczny.

Warto w tym kontekście wspomnieć o innym podejściu, które w glottodydaktyce rozpowszechniło się na szeroką skalę, a mianowicie komunikacyjnym. Nie jest w nim wyraźnie wyeksponowany wpływ kultury na język (Mihułka, 2014), co więcej uwaga skupia się tutaj przede wszystkim na kulturze docelowej, a kompetencja uczącego się winna osiągnąć idealny poziom użytkownika natywnego (Białek, 2017). Jednak różnorodność materiałów dydaktycznych o charakterze autentycznym (Puren, 1988), skoncentrowanych na dyskursach funkcjonujących w danym społeczeństwie, pozwala na zaobserwowanie złożonego charakteru i różnych wymiarów kultury. To natomiast sprawia, że staje się ona niejako „bliższa”, bardziej „dostępna” (co wydaje się utrudnione przy koncentracji na kulturze „wysokiej”, jak np. w przypadku metody gramatyczno-tłumaczeniowej). Również zauważalny zwrot w kierunku upodmiotowienia ucznia sprawia, że on i jego tożsamość - oraz kultura - zaczynają odgrywać coraz istotniejszą rolę w nauczaniu/uczeniu się języka obcego, choć w przypadku podejścia komunikacyjnego nie jest to jeszcze wyraźnie zaakcentowane.

Jak z tego wynika, tradycyjne podejścia glottodydaktyczne - w ramach rozwijania $\mathrm{KI}$ - kładą akcent głównie na przekazywanie wiedzy deklaratywnej (Myczko, 2005), niepowiązanej zazwyczaj z elementem wiedzy proceduralnej czy czynnikami afektywnymi. Przede wszystkim jednak skupiają się na kulturze docelowej. Niewiele miejsca (bądź wcale) poświęca się na uświadamianie funkcjonowania kultury własnej uczących się i tożsamości w niej ukształtowanej, co znacznie ułatwiłoby refleksję metakulturową. Na te tendencje Byram zwracał uwagę już w 1991 roku, pisząc, że „nauczanie języka obcego (...) zwyczajowo zajmuje się tylko jednym językiem i kulturą, a nauczanie ogólnych pojęć jest zwykle postrzegane jako okazjonalne"7 (Byram, 1991: 36; tłumaczenie własne autorki).

Widoczny progres $w$ tym obszarze widać wraz z rozwojem podejścia interkulturowego. O ile wcześniejsze metody i podejścia koncentrowały się na kulturze docelowej, o tyle dydaktyka interkulturowa podkreśla również rolę kultury własnej uczących się (Białek, 2017), co sprzyja budowaniu postawy refleksyjnej, opartej na świadomości (meta)kulturowej i wrażliwości (dwóch ogniw KI w propozycji Wilczyńskiej, 2005). Przełomowy charakter tego paradygmatu trafnie podsumowuje Byram (1991: 36), twierdząc, że „chociaż nauczyciele języków obcych mogą opierać się temu, by akcentować kulturę własną oraz osobowość, „ja” uczniów, nie powinno być to dłużej lekceważone.

\footnotetext{
${ }^{7}$ Ang.: „Foreign language teaching, on the other hand, is traditionally concerned with only one language and culture and the teaching of general concepts would normally be seen as incidental".
} 
Kompetencja interkulturowa oraz lepsze zrozumienie siebie są dalekie od wzajemnego wykluczenia"8 (tłumaczenie własne autorki).

Dydaktyczna koncepcja Byrama (1991) integrująca nauczanie kultury oraz języka stanowi pewien „prototyp” dla budowania kolejnych modeli KI, w których odchodzi się od klasycznej metody podawczej, skupionej na przekazywaniu wiedzy deklaratywnej dotyczącej kultury docelowej. Lansuje się w nich w zamian kompleksowe podejście do zadania, wychodząc od krytycznej świadomości kultury - również własnej. Koncept świadomości językowej implikuje nabywanie umiejętności związanych z opanowywaniem języka jako systemu zasad gramatycznych, syntaktycznych, leksykalnych itd. wraz z analizą samego charakteru języka jako zjawiska społeczno-kulturowego. Ten komponent nazwany language awareness zwraca uwagę na kulturowe oraz dyskursywne uwarunkowania języka, których obserwacja powinna dotyczyć również własnego języka i własnej kultury, które stają się swego rodzaju „pomostem” (Byram, 1991). Z drugiej strony, byramowska świadomość kulturowa uzupełnia niejako tę językową - kieruje uwagę w stronę zjawisk i wartości kulturowych, które znajdują swoje odzwierciedlenie w języku. Ten element zwany cultural awareness związany jest ze zgłębianiem schematów, wzorców funkcjonowania kultur i odnosi się również do kultury własnej uczących się. Postulowany przez Byrama i Zarate (1994) oraz przez Kramsch (1998) modelowy rozmówca interkulturowy (ang. intercultural speaker) odznacza się właśnie taką kompetencją, która opiera m.in. na analizie własnego funkcjonowania jako podmiotu kulturowego, dzięki czemu możliwe staje się dotarcie do ogólnych mechanizmów kulturowych i budowanie świadomości obejmującej wyższy poziom ogólności ${ }^{9}$. Wydaje się, że ta koncepcja glottodydaktyczna położyła podwaliny pod zmiany w kierunku kompleksowego rozwijania $\mathrm{KI}$, nie ignorując zasobów (kulturowych) uczących się, a postrzegając je jako wartościowy punkt odniesienia dla rozwijania "kulturowej metaanalizy”.

\footnotetext{
${ }^{8}$ Ang.: "Although foreign language teachers may resist the emphasis on the learners' own culture and selves, it should not be dismissed without more ado. For an intercultural competence and a deeper self-understanding are far from being mutually exclusive".

${ }^{9}$ Zgodnie z myślą Byrama (1991: 23): „(...) By pomóc uczniom zrozumieć tę kulturową wiedzę, nauczyciel najpierw porównałby ją do ich własnej, niewyartykułowanej kompetencji kulturowej i zacząłby ich uświadamiać co do ogólnej natury kulturowego zachowania” (tłumaczenie własne autorki, ang.: „)...) In order to help pupils to understand that cultural knowledge, the teacher would compare it with their own unarticulated cultural competence and begin to make them aware of the nature of cultural behavior in general").
} 


\section{Kultura własna a rozwijanie KI współcześnie}

W dzisiejszej perspektywie skłaniamy się do podejmowania kwestii KI w nieco odmienny sposób niż dawniej, na co silny wpływ ma m.in. współcześnie obserwowalna heterogeniczność kultur i ich ciągłe przenikanie się (Wilczyńska, 2005). Zmiany te wynikają również w jasny sposób z przedstawionej w artykule ewolucji modeli glottodydaktycznych. Oznacza to, że obecnie - co zapoczątkował Byram już na początku lat 90. - zdecydowanie bardziej podkreśla się rolę tożsamości kulturowej uczących się w procesie kompleksowego nauczania/uczenia się języka obcego.

W świetle KI świadomość odwoływania się do tej tożsamości jest więc kluczowa, by możliwe stało się zrozumienie własnego działania i dotarcie do własnych standardów (Thomas, 2010) czy skryptów kulturowych (Wierzbicka, 1999), do których często implicytnie się odnosimy (ma to związek z pewnego rodzaju nieuświadomioną „wielowarstwowością” kultury i jej modelem jako „góry lodowej"; por. Weaver, 1986). Otóż wydaje się, że dopiero odkrycie i zrozumienie sposobów własnego funkcjonowania jako podmiotu kulturowego ułatwia dotarcie do motywów i pobudek Drugiego, który, przyjmując określoną postawę, bazuje na własnych normach i wartościach społeczno-kulturowych (por. Bechtel, 2003; Busch, 2005). W ten sposób można też zaobserwować i uchwycić mechanizmy, według których kultury działają w ogóle, a także zasady generatywne i organizacyjne, które nimi rządzą (Venel Guignard, 2012), co przekładać się może na szerszą perspektywę $w$ chwili interakcji z Drugim.

Jak trafnie podsumowuje aktualne tendencje Mihułka (2014: 84), w KI „nie chodzi zatem już tylko o wiedzę o kulturze np. Niemiec, a raczej świadomość swej własnej kultury, lecz także o wiedzę dotyczącą funkcjonowania kultur w ogóle" czy „świadomość zjawisk kulturowych w ogóle” (Karpińska-Musiał, Orchowska, 2019: 399), jak również o zrozumienie zjawiska kulturowości (por. Wilczyńska i in. 2019: 122). W momencie spotkania z inną kulturą konieczna jest wiedza nie tylko o niej, ale też o kulturze własnej, gdyż to właśnie ta pozwala na interpretację odmiennego zachowania i reakcji (Mihułka, 2014) oraz na negocjacje kulturowych konceptualizacji (por. Myczko, 2005; Sharifian, 2013). Warto również zaznaczyć, że samo pojęcie interkulturowy/a poprzez swój przedrostek inter- (łac. między, wspót-) sugeruje pewną relację, współzależność: jest to więc swego rodzaju wypadkowa, wielostronny związek tego, co „własne” i tego, co „inne” ${ }^{10}$ (por. ZatorPeljan, 2014). KI implikuje tym samym równoczesną refleksję nad "własnym"

\footnotetext{
${ }^{10}$ Ma to związek ze zjawiskiem tzw. nakładania się kultur (ang. cultural overlap), tutaj rozumianych jako interakcji między kulturą własną a obcą (por. Thomas, 2010; Spychała-Wawrzyniak, 2016; Kuchta, 2017).
} 
i nad „innym” - nad tym, jak odnośne kultury funkcjonują, do jakich standardów i wartości się implicytnie odnoszą, według jakich schematów działają, a to w konsekwencji pozwala na zaobserwowanie pewnych ogólnych mechanizmów organizacyjnych. W tej perspektywie uświadomienie sobie funkcjonowania własnej kultury i tożsamości stanowi punkt wyjścia dla analizy na wyższym poziomie ogólności. Świadomość metakulturowa, która się w ten sposób konstruuje, umożliwia wnikliwszą obserwację kulturowych przejawów w podejściu Drugiego, zwraca też uwagę zwłaszcza na wymiar werbalny (por. Charaudeau, 2001; Kerbrat-Orecchioni, 2005), szczególnie interesujący w kontekście glottodydaktycznym.

\section{Zakończenie}

Reasumując: obecnie w glottodydaktyce zauważyć można spore zmiany w ukierunkowaniu kompleksowego rozwijania $\mathrm{Kl}$, postrzeganego obecnie jako proces, w którym należy brać pod uwagę tożsamość uczących się kształtowaną przez ich własną kulturę. Przedstawiona w artykule analiza różnych metod i podejść glottodydaktycznych pod tym kątem pozostawia z pewnością wiele pytań, zwłaszcza jeśli chodzi o praktyczne rozwiązania dydaktyczne. Pozwala ona jednak na krótką refleksję podsumowującą aktualne tendencje i potencjalne efekty związane z przyjęciem takiej postawy. $W$ tym kontekście warto przede wszystkim zaznaczyć raz jeszcze, że podejście interkulturowe, wzorowane na poglądach Byrama, w bardziej kompleksowy sposób traktuje proces nauczania/uczenia się języka obcego, w tym także doskonalenia Kl. Klasyczne koncepcje, kładąc nacisk na wiedzę deklaratywną - co niejako zrozumiałe, bo przecież stanowi ona jedną z podstaw odnośnej kompetencji - dotyczącą kultury związanej z danym językiem obcym, nie wspierają rozwijania właściwie ukierunkowanej postawy refleksyjnej, a to w prosty sposób może prowadzić do powstawania krzywdzących stereotypów. Taka refleksja wymaga odpowiedniego wypracowania, opartego na obserwacji organizacji i funkcjonowania kultur oraz kształtowanych przez nie podmiotów, która to analiza wydaje się najbardziej naturalna i dostępna w odniesieniu do własnej kulturowej tożsamości i zbiorowości.

Obecnie popularyzuje się takie modele rozwijania KI, które opierają się na pracy nad ogólną wiedzą i świadomością co do złożoności kultur oraz ich systemowego charakteru. To z kolei przekłada się na całościowy rozwój jednostki, czyli uczącego się, który udoskonala swoje umiejętności metaanalizy możliwe do wykorzystania w innych dziedzinach czy sferach życia. Dzięki tak wypracowanemu podejściu do KI, nauka języka obcego staje się „pełniejsza” - zdaje się akcentować kluczowe zrozumienie „rzeczywistości społecznej”, o której mówił Sapir (1978), postulując konieczność kształtowania świadomości opartej na badaniu własnej kultury i tożsamości. 


\section{BIBLIOGRAFIA}

Bechtel M. (2003), Interkulturelles Lernen beim Sprachenlernen im Tandem. Eine diskursanalytische Untersuchung. Tübingen: Gunter Narr Verlag.

Białek M. (2017), Kształcenie wrażliwości interkulturowej w edukacji językowej. „Języki Obce w Szkole”, nr 4, s. 14-20.

Bolten J. (2006), Kompetencja interkulturowa a kształcenie kompleksowe. Teoria i praktyka przekazu kompetencji interkulturowej w biznesie, (w:) Mackiewicz M. (red.), Dydaktyka języków obcych a kompetencja kulturowa i komunikacja interkulturowa. Poznań: Wydawnictwo WSB, s. 37-46.

Boski P. (2009), Kulturowe ramy zachowań społecznych. Podręcznik psychologii międzykulturowej. Warszawa: PWN.

Busch D. (2005), Interkulturelle Mediation. Eine theoretische Grundlegung triadischer Konfliktbearbeitung in interkulturell bedingten Kontexten. Frankfurt am Main: Peter Lang.

Byram M. (1991), Teaching culture and language: towards an integrated model, (w:) Butjes D., Byram M. (red.), Mediating Languages and Cultures. Towards an Intercultural Theory of Foreign Language Education, Clevedon: Multilingual Matters, s. 17-30.

Byram M., Zarate G. (1994), Definitions, objectives and assessment of sociocultural competence. Strasbourg: Council of Europe.

Charaudeau P. (2001), Langue, discours et identité culturelle. „Éla. Études de linguistique appliquée", nr 123-124, s. 341-348.

Charaudeau P. (2009), L'identité culturelle entre soi et l'autre, (w) Materiały konferencyjne z Louvain-la-Neuve 2005. Online: http://www.patrick-ch araudeau.com/L-identite-culturelle-entre-soi-et.html [DW 28.12.2019].

Golka M. (1992), Kultura jako system. Poznań: Ośrodek Wydawnictw Naukowych. Grucza F. (1989), Język a kultura, bilingwizm a bikulturyzm: lingwistyczne i glottodydaktyczne aspekty interlingwalnych i interkulturowych różnic oraz zbieżności, (w) Grucza F. (red.), Bilingwizm, bikulturyzm - implikacje glottodydaktyczne. Warszawa: Wydawnictwo Uniwersytetu Warszawskiego, s. 9-49.

Hall E. T. (1976), Ukryty wymiar. Warszawa: Państwowy Instytut Wydawniczy. Karpińska-Musiał B., Orchowska I. (2019), Międzykulturowość jako przestrzeń dla transdyscyplinarnej metaanalizy w glottodydaktyce i pedagogice międzykulturowej - pola wspót-/niezależności pojęć, paradygmatów i celów kształcenia. „Neofilolog”, nr 52(2), s. 389-410.

Keesing R. (1974), Theories of culture. "Annual Review of Anthropology”, nr 3, s. 73-97.

Kerbrat-Orecchioni C. (2005), Le discours en interaction. Paris: Armand Colin. 
Kramsch C. (1991), Culture in language learning: a view from the United States, (w:) De Bot K., Ginsberg R., Kramsch C. (red.), Foreign Language Research in Cross-cultural perspective. Amsterdam: John Benjamins, s. 217-240.

Kramsch C. (1998), The Privilege of the Intercultural Speaker, (w) Byram M., Fleming M. (red.), Language Learning in Intercultural Perspective. Approaches Through Drama and Ethnography. Cambridge: Cambridge University Press, s. 16-32.

Kuchta J. T. (2017), Kształcenie kompetencji interkulturowych w wybranych podręcznikach do nauki języka polskiego jako obcego. „Roczniki Humanistyczne", tom LXV, nr 10, s. 59-71.

Mackiewicz M. (2005), Jeszcze raz o modelu z Tybingi. Wsparcie kompetencji interkulturowej czy utrwalenie stereotypów? (w) Mackiewicz M. (red.), Dydaktyka języków obcych a kompetencja kulturowa i komunikacja interkulturowa. Poznań: Wydawnictwo WSB, s. 55-62.

Matsumoto D., Juang L. (2007), Psychologia międzykulturowa. Gdańsk: GWP. Mihułka K. (2014), Dylematy współczesnej glottodydaktyki: język - kultura, interlingwalizm - interkulturowość. „Języki Obce w Szkole”, nr 3, s. 78-87.

Myczko K. (2005), Kompetencja interkulturowa jako cel kształcenia językowego, (w) Mackiewicz M. (red.), Dydaktyka języków obcych a kompetencja kulturowa i komunikacja interkulturowa. Poznań: Wydawnictwo WSB, s. 27-35. Neuner G. (2003), Les mondes socioculturels intermédiaires dans l'enseignement et l'apprentissage des langues vivantes, (w) Byram, M. (red.), La compétence interculturelle, Strasbourg: Éditions du Conseil de l'Europe, s. 15-66. Polok K. (2006), Glottospołeczne elementy akulturacji. Od teorii do praktyki. Katowice: Oficyna Wydawnicza GWSH.

Porcher L. (1988), Programmes, progrès, progressions, projets dans l'enseignement/apprentissage d'une culture étrangère. „Études de linguistique appliquée", nr 169, s. 91-100.

Puren Ch. (1988), Histoire des méthodologies de l'enseignement des langues. Paryz: Nathan-CLE International.

Rada Europy (2003), Europejski system opisu kształcenia językowego: uczenie się, nauczanie, ocenianie. Warszawa: Centralny Ośrodek Doskonalenia Nauczycieli.

Sapir E. (1978), Kultura, język, osobowość. Warszawa: Państwowy Instytut Wydawniczy.

Sharifian F. (2013), Globalisation and developing metacultural competence in learning English as an International Language. "Multilingual Education”, nr 3. Online: https://doi.org/10.1186/2191-5059-3-7 [DW 22.04.2020].

Spychała-Wawrzyniak M. (2016), Trening interkulturowy podczas lekcji języka obcego na przykładzie języka hiszpańskiego, (w) Jaroszewska A. i in. (red.), Wielojęzyczność i międzykulturowość na lekcji języka obcego. 
Między teorią a praktyką nauczania. Warszawa: Instytut Romanistyki UW, s. 77-94.

Thomas A. (2001), Fremdheitskonzepte in der Psychologie als Grundlage der Austauschforschung und der interkulturellen Managerausbildung, (w:) Wierlacher A. (red.), Kulturthema Fremdheit. Leitbegriffe und Problemfelder kulturwissenschaftlicher Fremdheitsforschung. München: Indicium Verlag, s. 257-281.

Thomas A. (2010), Culture and Cultural Standards, (w:) Thomas A. i in. (red.), Handbook of Intercultural Communication and Cooperation. Göttingen/Oakville: Vandenhoeck \& Ruprecht, s. 17-27.

Venel Guignard M.-D. (2012), La culture de l'Autre: un miroir ? „Synergies Mexique", nr 2, s. 71-82.

Weaver G. (1986), Understanding and coping with cross-cultural adjustment stress, (w) Paige M. (red.), Cross-cultural Orientations: New Conceptualizations and Applications. Lanham, MD: University Press of America, s. 111-145.

Wierzbicka A. (1999), Język - umyst-kultura. Warszawa: Wydawnictwo Naukowe PWN.

Wilczyńska W. (2005), Czego potrzeba do udanej komunikacji interkulturowej? (w) Mackiewicz M. (red.), Dydaktyka języków obcych a kompetencja kulturowa i komunikacja interkulturowa. Poznań: Wydawnictwo Wyższej Szkoły Bankowej, s. 15-26.

Wilczyńska W. i in. (2019), Komunikacja interkulturowa. Wprowadzenie. Poznań, Wydawnictwo Naukowe UAM.

Zator-Peljan J. (2014), Wpływ kultury własnej na postrzeganie innych obszarów kulturowych. „Języki Obce w Szkole”, nr 1, s. 32-38. 